\title{
An Empirical Study on the Influencing Factors of Knowledge Sharing in Project Context
}

\author{
Daojiang WEI \\ School of Civil Engineering, Xi'an University of Architecture and Technology, Xi'an 710055, China; \\ School of Civil Engineering, Hubei University of Art and Science, Xiangyang 441053, China \\ E-mail: wxx850120@aliyun.com \\ Huimin LI \\ School of Civil Engineering, Xi'an University of Architecture and Technology, Xi'an 710055, China \\ E-mail: li_huimin2005@126.com
}

\begin{abstract}
The article makes a comparative research on the effect of leader supporting, interpersonal relationship, knowledge sharing mechanisms and organizational incentive on the formal and informal knowledge sharing in the project context. Through the establishment of structural equation model, some conclusions have been reached as follows: Firstly, leader supporting positively influences both formal and informal knowledge sharing, whereas the interpersonal relationship partly mediates between leader supporting and informal knowledge sharing; Moreover, the interpersonal relationship has a significant effect on both formal and informal knowledge sharing; Sharing mechanisms can significantly promote formal knowledge sharing, but there is no direct impact on informal side. Instead, the interpersonal relationship plays a fully mediating role between sharing mechanism and informal sharing; Finally, organizational incentive has a significant promotion on formal sharing, but negatively influences the informal sharing.
\end{abstract}

Keywords construction project; formal knowledge sharing; informal knowledge sharing; influencing factors

\section{Introduction}

In the contemporary knowledge-intensive economy, organizations' competitiveness relies heavily on their ability to leverage knowledge. However, organizations are not able to create knowledge themselves. They depend on their employees to create, share and apply knowledge in work process. Since the knowledge is created by the employees, and resides in individuals' heads, so the organization can't achieve anything if the employees reluctant to share their knowledge. Thus, what are the antecedents and how to predict employees' knowledge sharing behavior has been regarded as crucial challenges confronted by the organizations.

For a long time, the construction industry attracted widespread knowledge managers' attention for its project-based mode of production and single-piece production characteristics ${ }^{[1-6]}$. As early as in 1991, Srikanth proposed that knowledge has an important transitive function in

Received December 11, 2013, accepted February 12, 2014 
project management activities, and suggested adopting knowledge strategy in project management to control the phenomenon of project "island" [7]. However, due to the engineering project is a temporal activity, the knowledge and experience acquired in the construction procedure often loss with the project completion, therefore, it 's hard to realize the propagation and reuse of these knowledge. In recent years, scholars have recognized that effective knowledge sharing in project implementation has positive effect in communication and collaboration between departments, the identification and transfer of project knowledge can avoid "reinventing the wheel" in the subsequent projects, and thus improving the operational level of the whole organization.

The research of knowledge sharing in the context of project is still in an initial stage at present. Moreover, most of the available literatures in knowledge sharing field have been carried out in western countries, clearly, only few studies have been conducted in Chinese project organization. Quite different from individualistic culture of Western countries, China has a highly collectivistic culture that group interests and collective good takes precedence over individual interests. Therefore, study on the determinants to predict individual's knowledge sharing behavior within a Chinese context can uncover many implications for both practitioners and managers. Such a research especially in the construction industry, which involves a variety of skills and expertise, can help providing appropriate conditions for organizational knowledge sharing.

This paper is organized into five sections. The following section provides a review of literature on the concepts of knowledge sharing and the crucial factors comprising leader supporting, interpersonal relationship, knowledge sharing mechanisms and organizational incentive that influence knowledge sharing behavior of individuals in the organizational context respectively. On the basis of the description above, six research hypotheses and the conceptual model were developed. Section 3 discusses the development of survey instrument to measure the constructs in the research model and presents the results of data analysis. Section 4 discusses the findings along with reflects on the theoretical and practical implications. Section 5 covers the limitations of this study and recommendations for future research.

\section{Theoretical background and hypothesis}

\subsection{Knowledge sharing}

Review of the extant literature on knowledge sharing indicates that there is no all-round definition of knowledge sharing. Many researchers have defined knowledge sharing from their own point of view. Some researchers even considered knowledge sharing, knowledge flows and

knowledge transfer as exchangeable terms and defined them as such. For instance, $\operatorname{Lin}^{[8]}$ defined knowledge sharing as a two-way communication that employees from different parts within an organization or across organizations, through various channels of knowledge exchange and discussion between each other, which aims at increasing the utility value of knowledge and creating new knowledge through the exchange process. Wickramasinghe ${ }^{[9]}$ linen knowledge sharing to knowledge transfer and define it as the process of disseminating knowledge throughout the organization. Similarly, Szulanski ${ }^{[10]}$ and Teng ${ }^{[11]}$ believe that knowledge sharing refers to the transition of knowledge from the provider to the receiver within the organization. This study treats knowledge sharing as a process that project members share their knowledge with 
other members freely in the context of a project.

Generally, there are three factors influencing the individual's knowledge sharing behavior: knowledge factors, personal factors and environmental factors. Knowledge factors mainly exert its impact on the process of knowledge sharing through its own characteristics (explicit knowledge or implicit knowledge). Studying the impact of individual's characteristics, such as the attitude, perception, intention and goal orientation on knowledge sharing behavior is the content of personal factors, which based on the theories of motivation, causing theory and planned behavior theory ${ }^{[12-14]}$. Environmental factors focus on the environment of knowledge sharing, highlight the effect of external environment such as organizational culture, leadership style, technical support, and sharing mechanisms on the knowledge sharing behavior of the knowledge owner. Although the scholars conducted considerately about the factors affecting knowledge sharing, but there are still some conflicts among the available literatures. For example, in relation to the effect of incentives on knowledge sharing, Wickramasinghe et al ${ }^{[9]}$ believe that incentives will play a very critical role in promoting knowledge sharing among staffs. However, the empirical study of Jewels et al ${ }^{[15]}$ demonstrated that the effect of organizational incentives in promoting individual's knowledge sharing is not significant. Even Bock et $\mathrm{al}^{[16]}$ found that the organizational incentives, to a certain extent, inhibit the individual's willingness to share knowledge, and thus preventing knowledge sharing behavior. According to Kremer and other scholars' opinion, knowledge sharing could be divided into formal and informal occasions, maybe the sharing motivation and behavior of knowledge owner are not the same in different occasions ${ }^{[17]}$. Therefore, in order to exert a more saliently understanding of the influencing mechanism on knowledge sharing, this paper divides knowledge sharing into formal sharing and informal sharing based on the different occasions, and moreover, conducts a comparative study on the effect of different factors on the both cases.

\section{$2.2 \quad$ Leader supporting}

Leadership has a decisive influence on the order formation and goals realization, which is also affecting knowledge sharing within the organization. By means of empirical research many scholars confirm the fact that leader supporting has a positive influence in facilitating knowledge sharing. As Srivastava et al ${ }^{[18]}$ said that knowledge sharing does not happen spontaneously, the leadership played a key role in the organization.

Leader supporting for knowledge sharing is not only reflected in the aspect of physical and material side, such as setting up specialized positions for knowledge sharing, adopting advanced information techniques, but also giving emphasis on knowledge sharing in terms of management conception. Lin $^{[19]}$ demonstrated that the decentralization of authority to employees and the tolerance for learners' errors have a significant influence on promoting employees' knowledge sharing behavior within the organization. Wickramasinghe et al ${ }^{[9]}$ said that the leader of organization should encourage and assist the exchanging knowledge among employees, and create a harmonious atmosphere to promote knowledge sharing. Fong and $\mathrm{Chu}^{[20]}$ carried out knowledge sharing research in the Hong Kong Construction Industry and found that supporting and commitment of senior managers ranked No.2 in 15 crucial influencing factors of knowledge sharing. The results of previous studies show the decisive effect of leader supporting on the promotion of knowledge sharing. Therefore, on the basis of the descriptions above, the following 
hypothesis are proposed:

H1a: Leader supporting positively influences informal knowledge sharing within the construction project.

H1b: Leader supporting positively influences formal knowledge sharing within the construction project.

\subsection{Interpersonal relationship}

Interpersonal relationship is an indispensable part in people's social life in China, which rooted in the confucian ethics culture with characteristics of reciprocity, effectiveness, transferability and privacy. It is an important resource of allocation mechanism; Chinese always take "what kind of relationship with other people" as an important reference for the allocation of resources ${ }^{[21]}$. Therefore, the relationship between knowledge providers and recipients, to a great extent, determines the owner's knowledge sharing behavior in the Chinese cultural context. Zhao et al ${ }^{[22]}$ put forward the developing direction of knowledge sharing with Chinese localized theory from the perspective of individual's motivation, and admitted that the effect of interpersonal relationship on behaviors' motivation has promising prospect in the context of Chinese culture. $\mathrm{Cao}^{[23]}$ conducted a research on the effect of interpersonal relationship on knowledge sharing and concluded that interpersonal relationship plays a fully mediated role in knowledge controlling and knowledge sharing. However, the previous literatures didn't distinguish the effect of interpersonal relationship between the formal and informal knowledge sharing. In addition, most of them were not conducted under the project context. Therefore, this paper attempts to study the effect of interpersonal relationship on knowledge sharing behavior in project environment, thus proposes the following hypothesis:

H2a: The interpersonal relationship positively influences informal knowledge sharing.

H2b: The interpersonal relationship positively influences formal knowledge sharing.

\subsection{Knowledge sharing mechanisms}

"Mechanism" is a kind of intrinsic coordinated manner and adjusting principle, which normalizes the linkage between different elements within an organization to maintain its potential function and further makes it become into explicitly specific functions ${ }^{[24]}$. As is often the case, knowledge sharing mechanisms include brainstorming, workshop, group training, face to face interaction, conference presentation, post project evaluation and so on. And related to that, there are varieties of knowledge sharing mechanisms, such as video conferencing, newsgroups, Wiki and E-mail. Different knowledge sharing mechanisms are adopted by organization in different countries and thus under different cultural backgrounds. For instance, Fong and $\mathrm{Chu}^{[20]}$ found that construction industry in Hong Kong use formal knowledge channel more frequently, such as on-site conferencing and video conferencing to share knowledge, meanwhile, the other ways such as newsgroups, online discussion are rarely used. In contrast, the UK's construction industry often use informal communication, chatting and telling stories etc., followed by telephone communication and video conferencing. However, the mechanisms relating to on-site knowledge sharing meetings, online discussions, etc. are almost never employed. Jones and Borgman ${ }^{[25]}$ found that in many industrial enterprises in the United States, E-mail is the most common way of knowledge sharing, but the forum discussions, etc. is rarely used. 
Taken more appropriate mechanism is not only associated with the context of the industry and country, but also related to the organizational structure and enterprises' culture. Different mechanisms will result in very different effects on knowledge sharing within the organization. Therefore, this paper makes a research on the influence of mechanism on employees' knowledge sharing behavior in the context of the construction industry in China and puts forward the following assumptions:

H3a: Knowledge sharing mechanism positively influences informal knowledge sharing within the construction project.

H3b: Knowledge sharing mechanism positively influences formal knowledge sharing within the construction project.

\subsection{Organizational incentive}

Organizational incentive indicates what the organization values shape employee behaviors. Organizational incentive can range from monetary incentives such as increased wages and bonuses to non-monetary awards such as promotions and job security. Several scholars have conducted empirical researches on the relationship between incentive and knowledge sharing, but no all-round conclusion has been achieved. For example, Wickramasinghe et al ${ }^{[9]}$ as a representative proposed that organizational incentive is more effective than technical support in spurring knowledge sharing. Bartol and Srivastava ${ }^{[26]}$ also emphasized the importance of the incentive in stimulating employees' knowledge contribution to the organizational database and formal exchanging of experience among members. In contrast, Jewels and Ford ${ }^{[15]}$ demonstrated that the organizational incentive can't facilitate knowledge sharing behavior dramatically. Individuals are more likely to share their knowledge in a sense of belonging, identity, and not just for the sake of getting some form of return. Fong and $\mathrm{Chu}^{[20]}$ also found that instead of eager to earn material rewards, organizational members sharing knowledge in the UK construction industry are mainly to help other organizational members. Even Bock et al ${ }^{[16]}$ demonstrated that employees are willing to share their knowledge only when they feel the incentive (material or immaterial) exceeds the cost, therefore, the organization incentive will be in a certain extent inhibit individual's willingness to share knowledge and thereby hinder knowledge sharing.

Thus, the effect of organizational incentive on knowledge sharing is complex. Even though Bartol and Srivastava ${ }^{[26]}$ recognized the fact that organizational incentive has different effect on formal and informal knowledge sharing, but they did not make a further comparative research. Therefore, on the basis of previous researches, the following hypotheses are proposed:

H4a: organizational incentive positively influences on informal knowledge sharing.

H4b: organizational incentive positively influences on formal knowledge sharing.

On the basis of the hypotheses proposed above, further research model is presented in Figure 1.

\section{Research methodology}

\subsection{Questionnaire design}

The questionnaire was designed to measure the hypothesis mentioned above. The items of this study were developed by adapting measures that were previously validated by other 
researchers. The leader supporting and organizational incentive were measured by adapting Lin's ${ }^{[19]}$ study. Interpersonal relationship and informal knowledge sharing measurements were adapted from the study of Cao and Xiang ${ }^{[23]}$. Knowledge sharing mechanisms were measured using items derived from Wickramasinghe et al ${ }^{[9]}$. Items to measure formal knowledge sharing were developed based on Kremer's ${ }^{[17]}$ measure of "knowledge sharing behavior". Each item was measured on a five-point Likert scale, with 1 being "strongly disagree" and 5 being "strongly agree". All the items were compiled into a questionnaire for the pilot test.

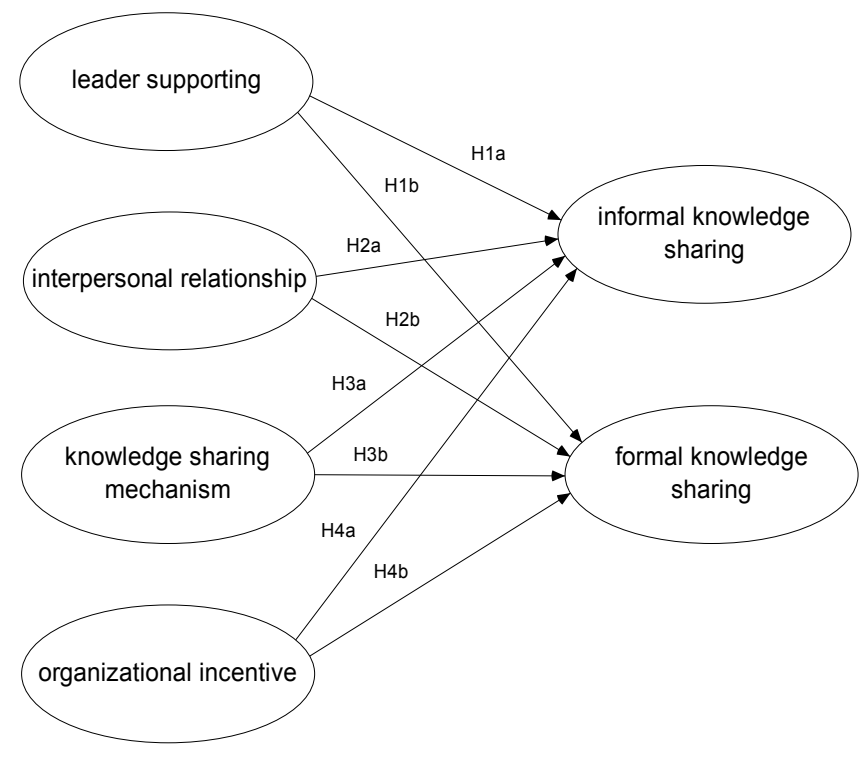

Figure 1 The research model based on hypothesis

\subsection{Pilot test}

In order to find possible composition or content problems in research questionnaire, 20 participants from five construction enterprises in Xi'an were asked to fill the questionnaire and comment on it. Based on their comments, the questionnaire was revised and then reconsidered using "back translation" technique with the guidelines provided by Francis et al ${ }^{[27]}$. And ultimately, a list of items for each of the measures is presented in the Appendix.

\subsection{Data collection}

A total of 325 questionnaires were distributed in 36 projects of 22 construction companies covering 15 large and medium-sized cities in China. In order to overcome the low response rate of survey in construction industry, the 2012 civil engineering graduates of Xi'an University of Architecture and Technology were selected as the contact persons, who generally worked in architecture, engineering and construction, and responsible for the distribution and recovery the questionnaires from his/her company. At last, of the 247 questionnaires returned, including 213 valid ones, yielding a response rate of 65.5 percent of the original sample, far ahead the standard of $20 \% \sim 30 \%$ recommended by Easterby-Smith ${ }^{[28]}$. Demographic data for the respondents are presented in Table 1. Most of the respondents were male, making up $87.3 \%$ of the sample. About $68.6 \%$ had a bachelor's degree, and $5.6 \%$ had a graduate degree. In terms of age, $15.0 \%$ 
of the respondents were 30 or under, $50.2 \%$ were in the age group $31 \sim 40,30.1 \%$ were in the age group $41 \sim 50$, and $4.7 \%$ were over 50 . With regard to job titles, $44.6 \%$ of the respondents were laborial staff, $40.9 \%$ were middle-level cadress, and $14.5 \%$ were top managers. The average tenure of the respondents with their current employer was 8.5 years (Std. Dev. $=5.2$ years). These demographics are presented in Table 1.

Table 1 Demographic attributes of the respondents

\begin{tabular}{|c|c|c|}
\hline Characteristic & Number & Percentage \\
\hline \multicolumn{3}{|l|}{ Gender } \\
\hline Male & 186 & $87.3 \%$ \\
\hline Female & 27 & $12.7 \%$ \\
\hline \multicolumn{3}{|l|}{ Educational level } \\
\hline High school & 55 & $25.8 \%$ \\
\hline College or university & 146 & $68.6 \%$ \\
\hline Graduate school & 12 & $5.6 \%$ \\
\hline \multicolumn{3}{|l|}{ Age } \\
\hline$\leq 30$ & 32 & $15.0 \%$ \\
\hline $31 \sim 40$ & 107 & $50.2 \%$ \\
\hline $41 \sim 50$ & 64 & $30.1 \%$ \\
\hline$>50$ & 10 & $4.7 \%$ \\
\hline \multicolumn{3}{|l|}{ Job title } \\
\hline Laborial staff & 95 & $44.6 \%$ \\
\hline Middle-level cadress & 87 & $40.9 \%$ \\
\hline Top manager & 31 & $14.5 \%$ \\
\hline \multicolumn{3}{|l|}{ Tenure (years) } \\
\hline \multicolumn{3}{|l|}{ Mean: 8.5} \\
\hline Standard deviation: 5.2 & & \\
\hline
\end{tabular}

\subsection{Data analysis and results}

A two-phase analysis was performed. The measurement model was first examined using confirmatory factor analysis to examine reliability as well as convergent and discriminant validities of the model. Then the hypotheses were tested using a structural equation model.

\subsubsection{Measurement model}

The adequacy of the measurement model was assessed according to reliability as well as convergent and discriminant validities. The reliability of the measures for each of the six constructs was assessed on the basis of Cronbach's $\alpha$ coefficient. The value of this coefficient varied from 0.761 to 0.932 (see Table 2), exceeding the recommended level of 0.7.

Item reliability, composite reliability, and the average variance extracted were computed to assess the convergent validity of the questionnaire items. To determine the item reliability of each measure, the factor loading should be 0.5 or greater, which indicates a well-defined structure. 
Table 2 Reliability measures for the measurement model

\begin{tabular}{lcc}
\hline Construct & Cronbach's $\alpha$ & Number of questionnaire items \\
\hline Leader supporting & 0.915 & 4 \\
Interpersonal relationship & 0.932 & 4 \\
Knowledge sharing mechanism & 0.857 & 4 \\
Organizational incentive & 0.761 & 4 \\
Informal knowledge sharing & 0.899 & 4 \\
Formal knowledge sharing & 0.872 & 4 \\
\hline
\end{tabular}

As shown in Table 3 , all of the factor loadings were greater than 0.5, exceeding the acceptable level suggested by Hair et al ${ }^{[29]}$. To ensure adequate composite reliability, a value of 0.7 or greater was recommended by Nunnally ${ }^{[30-31]}$.

Table 3 Convergent validity of the measurement model

\begin{tabular}{|c|c|c|c|c|}
\hline Construct & Item & $\begin{array}{l}\text { Factor } \\
\text { loading }\end{array}$ & $\begin{array}{l}\text { Composite } \\
\text { reliability }\end{array}$ & $\begin{array}{c}\text { Average variance } \\
\text { extracted }\end{array}$ \\
\hline \multirow[t]{4}{*}{ Leader supporting } & LS1 & 0.92 & 0.95 & 0.82 \\
\hline & LS2 & 0.88 & & \\
\hline & LS3 & 0.89 & & \\
\hline & LS4 & 0.92 & & \\
\hline \multirow[t]{4}{*}{ Interpersonal relationship } & $\mathrm{IR} 1$ & 0.68 & 0.92 & 0.74 \\
\hline & IR2 & 0.81 & & \\
\hline & IR3 & 0.97 & & \\
\hline & IR4 & 0.94 & & \\
\hline \multirow[t]{4}{*}{ Knowledge sharing mechanism } & SM1 & 0.84 & 0.91 & 0.71 \\
\hline & SM2 & 0.82 & & \\
\hline & SM3 & 0.85 & & \\
\hline & SM4 & 0.87 & & \\
\hline \multirow[t]{4}{*}{ Organizational incentive } & OI1 & 0.75 & 0.84 & 0.57 \\
\hline & OI2 & 0.82 & & \\
\hline & OI3 & 0.71 & & \\
\hline & OI4 & 0.74 & & \\
\hline \multirow[t]{4}{*}{ Informal knowledge sharing } & IS1 & 0.87 & 0.94 & 0.81 \\
\hline & IS2 & 0.88 & & \\
\hline & IS3 & 0.94 & & \\
\hline & IS4 & 0.91 & & \\
\hline \multirow[t]{4}{*}{ Formal knowledge sharing } & FS1 & 0.78 & 0.9 & 0.7 \\
\hline & FS2 & 0.84 & & \\
\hline & FS3 & 0.84 & & \\
\hline & FS4 & 0.89 & & \\
\hline
\end{tabular}


The composite reliability $(\mathrm{CR})$ was calculated as indicated by Fornell and Larcker ${ }^{[32]}$, with results ranging from 0.84 to 0.95 , exceeding the critical value of 0.7 . The average variance extracted (AVE) measures the overall amount of variance attributed to the construct relative to the amount of variance attributed to measurement error. The AVE for each construct should be at least 0.5 , at which point the variance captured by the construct exceeds the variance due to measurement error ${ }^{[33]}$. The results are all above 0.5 , ranging from 0.57 to 0.82 . Overall, the measurement model exhibited appropriate convergent validity.

Discriminant validity was assessed by comparing the square root of the AVE for a given construct with the correlations between that construct and all others. If the square roots of the AVEs are greater than the off-diagonal elements in the corresponding rows and columns of the correlation matrix, this suggests that a construct is more strongly correlated with its indicators than with the other constructs in the model. The correlation matrix, but with the diagonal elements replaced by the square root of the AVE, is presented in Table 4.

Table 4 Correlation matrix and discriminant assessment

\begin{tabular}{ccccccc}
\hline & LS & IR & SM & OI & IS & FS \\
\hline LS & 0.91 & & & & & \\
IR & 0.31 & 0.86 & & & & \\
SM & 0.28 & 0.34 & 0.84 & & & \\
OI & 0.23 & 0.07 & 0.21 & 0.75 & & \\
IS & 0.13 & 0.74 & 0.12 & -0.17 & 0.9 & \\
FS & 0.61 & 0.24 & 0.54 & 0.57 & -0.09 & 0.84 \\
\hline
\end{tabular}

Notes: LS (leader supporting), IR (interpersonal relationship), SM (knowledge sharing mechanism), OI (organizational incentive), IS (informal knowledge sharing), FS (formal knowledge sharing).

As shown there, the square roots of all the AVEs are greater than the absolute values of the off-diagonal correlations in the corresponding rows and columns, confirming discriminant validity. This indicates that the constructs were more strongly related to their respective indicators than to other constructs in the model ${ }^{[32]}$.

All six constructs were measured using items in a questionnaire completed by a single respondent. Therefore, common-method variance could be an issue in this study. To test for the common-method variance, Harman's one-factor test was conducted. In this single-factor test, all items are subject to an exploratory factor analysis. Common-method variance is assumed if (1) a single factor emerges from unrotated factor solutions, or (2) a first factor explains the majority of the variance in the variables. Therefore, 24 items of the six constructs were entered together into a principal components factor analysis. This analysis produced six factors, explaining $77.02 \%$ of the variance, with the first factor explaining $24.02 \%$ of the variance. In addition, the authors examine the fit of the single-factor model, goodness-of-fit statistics for the single factor model are provided in Table 5 .

All of the fitness index didn't satisfy the recommended value, which implied the single-factor model was highly insignificant and must be rejected. While these statistical tests didn't eliminate the possibility of common method variance, the authors contend that the small magnitude 
and insignificance of method variance provided substantial evidence that inter-item correlations were not driven purely by common-method variance.

Table 5 Evaluation of overall fitness of the three models

\begin{tabular}{lcccc}
\hline \multirow{2}{*}{ Fitness index } & Recommended & \multicolumn{3}{c}{ Value } \\
\cline { 3 - 5 } & value & $\begin{array}{c}\text { Single-factor } \\
\text { model }\end{array}$ & $\begin{array}{c}\text { Unmodified } \\
\text { model }\end{array}$ & $\begin{array}{c}\text { Modified } \\
\text { model }\end{array}$ \\
\hline$\chi^{2} / d f$ & $\leq 3.0$ & 10.68 & 2.63 & 2.27 \\
Goodness-of-fit index (GFI) & $\geq 0.9$ & 0.414 & 0.821 & 0.854 \\
Adjusted goodness-of-fit index (AGFI) & $\geq 0.8$ & 0.303 & 0.793 & 0.827 \\
Normed fit index (NFI) & $\geq 0.9$ & 0.444 & 0.885 & 0.933 \\
Comparative fit index (CFI) & $\geq 0.9$ & 0.126 & 0.837 & 0.906 \\
Root mean square error of & $\leq 0.08$ & 0.084 & 0.069 & 0.064 \\
approximation (RMSEA) & & & & $(635.743 / 242)$ \\
\hline
\end{tabular}

\subsubsection{Structural model}

The second step in the analytical process is to form the structural model by specifying the causal relations in accordance with the hypotheses. A structural equation modeling approach was used to test the fit between the research model and the input data. Goodness-of-fit indexes were critical for the evaluation of the entire model, in this study, six different indices were used for this purpose: the chi-square test, the goodness-of-fit index (GFI), the adjusted goodnessof-fit index (AGFI), the normed fit index (NFI), the comparative fit index (CFI), and the root mean square error approximation (RMSEA). The criteria that indicate a good fit for these six indices, along with the values of these indices derived from our study, are given in Table 5. As shown there, except the value of the chi-square test and the RMSEA, all other indices did not meet the suggested value. Through the model updating technology of the AMOS, the authors modified the model, and listed out the result of modified model in Table 5 too. It was obvious that the fitting level of the modified model improved significantly comparing to the unmodified. Although the GFI was slightly lower than the recommended value of 0.90 , it was close enough to suggest that the modified model was a reasonably good fit to the data.

Table 6 provided the results of the path analysis using AMOS 18.0, including the standardized path coefficients $(\beta)$, the critical ratios (t-values), and the p-values (in the case of hypotheses that were found to be supported).

As Table 6 demonstrates that six of the eight hypotheses were supported, of which the organizational incentive was found to negative effect on the informal knowledge sharing, but positively influence formal sharing. Contradictory to our hypothesis, after modifying the model, the knowledge sharing mechanism did no longer have a significant positive effect on the informal knowledge sharing within the project. Furthermore, leader supporting positively influence the informal knowledge sharing on the level of $0.5(\beta=0.113, p<0.5)$, the intensity of the relationship between interpersonal relationship and the informal knowledge sharing was the most significant $(\beta=0.748, p<0.001)$. We applied Baron and Kenny's ${ }^{[34]}$ logic to test 
Table 6 Hypothesis testing

\begin{tabular}{ccccc}
\hline Hypothesis & Relationship & Standardized path coefficient & Critical ratio (t-value) & Result \\
\hline Hypothesis 1a & $\mathrm{LS} \rightarrow \mathrm{IS}$ & $0.122^{*}\left(0.113^{*}\right)$ & $1.797(1.743)$ & Supported \\
Hypothesis 1b & $\mathrm{LS} \rightarrow \mathrm{FS}$ & $0.350^{* * *}\left(0.501^{* * *}\right)$ & $4.465(6.168)$ & Supported \\
Hypothesis 2a & $\mathrm{IR} \rightarrow \mathrm{IS}$ & $0.691^{* * *}\left(0.748^{* * *}\right)$ & $7.329(8.102)$ & Supported \\
Hypothesis 2b & $\mathrm{IR} \rightarrow \mathrm{FS}$ & $0.215^{* *}\left(0.312^{* * *}\right)$ & $3.277(4.206)$ & Supported \\
Hypothesis 3a & $\mathrm{SM} \rightarrow \mathrm{IS}$ & $0.039\left(0.165^{*}\right)$ & $0.531(2.062)$ & Not Supported \\
& & & & (Supported) \\
Hypothesis 3b & $\mathrm{SM} \rightarrow \mathrm{FS}$ & $0.332^{* * *}\left(0.268^{* *}\right)$ & $3.188(2.936)$ & Supported \\
Hypothesis 4a & $\mathrm{OI} \rightarrow \mathrm{IS}$ & $-0.038(-0.028)$ & $-0.659(-0.499)$ & Not Supported \\
Hypothesis 4b & $\mathrm{OI} \rightarrow \mathrm{FS}$ & $0.341^{* * *}\left(0.414^{* * *}\right)$ & $3.884(4.873)$ & Supported \\
\hline
\end{tabular}

mediating effects.

A variable is a mediator when it meets the following three conditions: (1) the independent variable significantly influences the mediating variable (path a), (2) the mediating variable significantly influences the dependent variable (path b), and (3) when path a and path $\mathrm{b}$ are controlled, a previously significant relation between the independent and the dependent variables is no longer significant (fully mediating role), or the degree of the significant change from strong to weak (partial mediating role). Hence, first the direct path from leader supporting to informal knowledge sharing is positive and significant $(\beta=0.324, p<0.001)$, so too the knowledge sharing mechanism to informal knowledge sharing $(\beta=0.165, p<0.5)$. When the interpersonal relationship is introduced as a mediator, the path from leader supporting to informal knowledge sharing is still significant $(\beta=0.25, p<0.05)$, but the degree of the significant was weaken. However, the path from knowledge sharing mechanism to informal knowledge sharing becomes not significant $(\beta=0.039, p>0.5)$, whereas both leader supporting and sharing mechanism strongly influences interpersonal relationship, and interpersonal relationship significantly influences informal knowledge sharing $(\beta=0.691, p<0.001)$. Hence, the relationship between leader supporting and informal knowledge sharing was partial mediated by the interpersonal relationship, which also fully mediated the relationship between sharing mechanism and informal sharing. The modified model and the result of path analysis were shown in Figure 2.

\section{Discussion and implications}

The purpose of the current study was to enhance the understanding of knowledge sharing in project teams in the context of architecture, engineering and construction in China. According to the perspective of Kremer ${ }^{[17]}$, the knowledge sharing could be classified into formal knowledge sharing and informal knowledge sharing. This study makes a comparative research about the effect of leader supporting, interpersonal relationship, knowledge sharing mechanisms and organizational incentives on the formal and informal knowledge sharing in the project context. The results indicated that the leader supporting has strongly positive effect on both formal and informal knowledge sharing within the project organization. But what was noteworthy that the interpersonal relationship partially mediated the relationship between leader supporting 


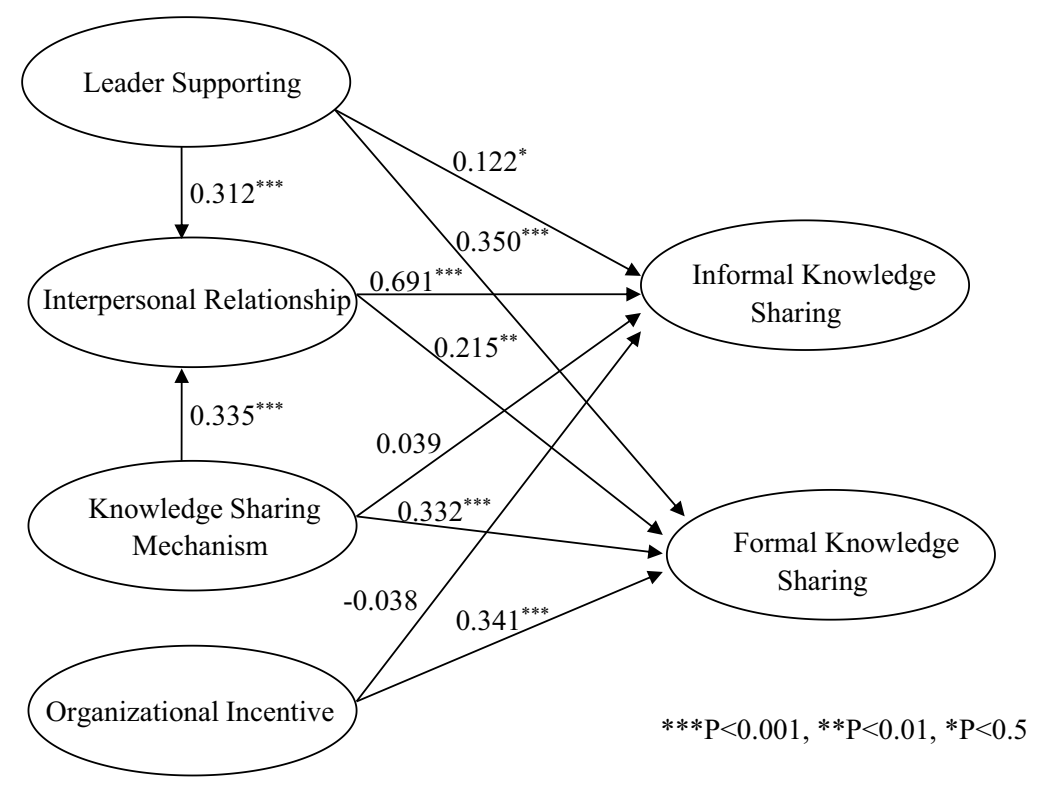

Figure 2 The modified model and results of analysis

and informal knowledge sharing, which indicated the project managers should not only provide their employees with the necessary facilities for knowledge sharing, but also need to highlight the cultural aspects, creating a good atmosphere of trust and collaboration, thereby achieving preferably informal knowledge sharing.

Interpersonal relationship is a special part of Chinese culture with mutual effects within both formal and informal systems. There are myriad features of the interpersonal relationship, such as mutual benefit, effectiveness, transitivity, privacy, commitment, intangibility, etc. The interpersonal relationship plays a role in Chinese organizations that can't be overstated ${ }^{[35-37]}$. From the study we can find that the interpersonal relationship has a positively significant effect on both formal and informal knowledge sharing. More specifically, the interpersonal relationship plays a part-mediating role between leader supporting and the informal knowledge sharing, and also plays a completely mediating role between knowledge sharing mechanism and the informal knowledge sharing. Thus it can be seen the critical role of the interpersonal relationship in knowledge sharing.

Knowledge sharing mechanism is a rather broad concept, which includes a variety of forms, such as work-group communications (bookmarking, brainstorming, collective problem solving), personal interactions (Wikis, e-mails, chatting). Previous studies suggested that individuals share knowledge through face-to-face dialogue and interact through technology mediated networks are effective in sharing knowledge in project teams ${ }^{[25,38-40]}$. However, the findings of our study suggest that the knowledge sharing mechanisms play positively significant role in promoting formal knowledge sharing in project context, but was completely mediated by the interpersonal relationship on the informal knowledge sharing. This may be due to the fact that the mechanisms using in our study are more formal, make it easier for participants to understand it as a formal sharing mechanism. Therefore, more empirical studies are needed to broaden the understanding in the future. 
It has always been a controversial topic about the influence of organizational incentive on knowledge sharing. For instance, Choi et al ${ }^{[41]}$ provide evidence that organizational incentive is more important than technical support in facilitating knowledge sharing. Bartol and Srivastava ${ }^{[26]}$ also suggest that monetary rewards could encourage knowledge sharing in the forms of individuals' contribution to databases, formal interactions within and between teams, and knowledge sharing across work units. However, Bock et $\mathrm{al}^{[16]}$ found that anticipated rewards exert a negative effect on individuals' knowledge sharing attitudes. The results of our study indicate the effect of organizational incentive on formal and informal knowledge sharing is different. Organizational incentive plays positive role on the formal knowledge sharing, which in consonance with the perspective of Choi et al ${ }^{[41]}$, Bartol and Srivastava ${ }^{[26]}$. As it requires additional time and effort (sharing cost) to summarize the experience into a report, or a file and then share it with other members of the organization. So can the incentive compensate to some extent for the cost of knowledge sharing, and of course effectively promote the knowledge sharing. But on the other hand, organizational incentive plays inhibitory role on the informal knowledge sharing within the organization, possibly due to the fact that knowledge sharing through face-to-face, e-mails or chatting are more appropriate to the informal situation, which can't be measured accurately, so it is can't be expected for a direct monetary reward. Consequently, from the perspective of human reason, they may prefer to choose a channel of quantifiable and rewarding to share their knowledge, thus inhibiting the informal knowledge sharing. Hence we can see that it's complicated of the relationship between organizational incentive and knowledge sharing, we should be cautious to adapt suitable strategy to achieve better knowledge sharing in practice.

\section{Limitations of the study and areas for future research}

While our results offer insights into the antecedents of knowledge sharing in project context in China, we acknowledge some limitations which offer starting points for future research. First, the survey sample was drawn from 325 employees in 36 projects, and only limited to the construction industry, the results of this study may not be generalizable to other industry. Hence, the research model should be tested further at a larger scale using samples from other industry. Second, as the data in this study was cross-sectional and not longitudinal in nature, some causal relationships could only be inferred, rather than empirically supported. Future research, however, will certainly benefit from collecting longitudinal data. A longitudinal examination of the multiple facets of the knowledge sharing would make the findings more robust. Alternatively, the enablers considered in this paper may not be comprehensive, future research should also incorporate the influence of other critical variables such as performance evaluations on knowledge sharing.

\section{Acknowledgements}

We thank the referees for their time and comments.

\section{References}

[1] Egbu C O, Robinson H S. Construction as a knowledge-based industry. Knowledge Management in Construction, 2005, 4: 31-49. 
[2] Kamara J M, Augenbroe G. Knowledge management in the architecture, engineering and construction industry. Construction Innovation, 2002, 2: 53-67.

[3] Ajzen I. Nature and operation of attitudes. Annual Review of Psychology, 2001, 52: 27-58.

[4] Wu Y, Zhu W D. An integrated theoretical model for determinants of knowledge sharing behaviours. Kybernetes, 2012, 41(10): 1462-1482.

[5] Dubois A, Gadde L. The construction industry as a loosely coupled system: Implications for productivity and innovation. Construction Management and Economics, 2002, 20: 621-631.

[6] Van Donk D P, Riezebos J. Exploring the knowledge inventory in project-based organizations: A case study. International Journal of Project Management, 2005, 23(1): 75-83.

[7] Srikanth R. Islands of control: A knowledge-based strategy for managing projects. New York, New York University, 1991.

[8] Lin D Q. Theory and practice of knowledge management. Beijing: Publishing House of Electronics Industry, 2005.

[9] Wickramasinghe V, Widyaratne R. Effects of interpersonal trust, team leader support, rewards, and knowledge sharing mechanisms on knowledge sharing in project teams. The Journal of Information and Knowledge Management Systems, 2012, 42(2): 214-236.

[10] Szulanski G. Exploring internal stickness: Impediments to the transfer of best practice within the firm. Strategic Management Journal, 1996, 17: 27-43.

[11] Teng J T C, Song S. An exploratory examination of knowledge sharing behaviors: Solicited and voluntary. Journal of Knowledge Management, 2011, 15(1): 104-117.

[12] Jeon S, Kim Y G, Koh J. An integrative model for knowledge sharing in communities-of-practice. Journal of Knowledge Management, 2011, 15(2): 251-269.

[13] Husted K, Michailova S, Minbaeva D B, et al. Knowledge-sharing hostility and governance mechanisms: An empirical test. Journal of Knowledge Management, 2012, 16(5): 754-773.

[14] Zhang P, Dang Y Z, Zhao X Z. An empirical analysis of influencing factors of employee's knowledge sharing behavior based on the theory of organizational behavior. Science of Science and Management, 2011, 32(11): $166-172$.

[15] Jewels T, Ford M. Factors influencing knowledge sharing in information technology projects. E-service Journal, 2006, 5: 99-117.

[16] Bock G M, Zmud R W, Kim Y G, et al. Behavioral intention formation in knowledge sharing: Examining the roles of extrinsic motivators, social-psychological forces, and organizational climate. MIS Quarterly, 2005, 29(1): 87-111.

[17] Kremer A L. Predictors of participation in formal and informal workplace learning: Demographic, situational, motivational and deterrent factors. George Mason University, 2005.

[18] Srivastava A, Bartol K M, Locke E A. Empowering leadership in management teams: Effects on knowledge sharing, efficacy and performance. Academy of Management Journal, 2006, 49(6): 1239-1251.

[19] Lin H F. Knowledge sharing and firm innovation capability: An empirical study. International Journal of Manpower, 2007, 28(3): 315-332.

[20] Fong P K, Chu L. Exploratory study of knowledge sharing in contracting companies: A sociotechnical perspective. Journal of Construction Engineering and Management, 2006, 132: 928-939.

[21] Sun L P. Guan Xi, social relationship and social structure. Sociological Studies, 1996, 5: 20-30.

[22] Zhao S S, Liao J Q, Zhang K J. Individual's knowledge sharing motivation: Review of the abroad studies and the development of localization theory. Journal of Information, 2010, 29(1): 114-122.

[23] Cao Y, Xiang Y. The impact of knowledge governance on knowledge sharing. Management Decision, 2012, 50(4): 591-610.

[24] Chen X, He J S. Study on the mutual transformation of personal knowledge and organizational knowledge and their mechanism. Journal of China University of Geosciences, 2004, 4(6): 10-14.

[25] Jones N B, Borgman R H. An exploratory study on knowledge sharing, information technologies and firm performance. OR Insight, 2007, 20(4): 10-21.

[26] Bartol K M, Srivastava A. Encouraging knowledge sharing: The role of organizational reward systems. Journal of Leadership \& Organizational Studies, 2002, 9(1): 64-77.

[27] Francis J J, Eccles M P, Johnston M, et al. Constructing questionnaires based on the theory of planned behaviour: A manual for health services research. Quality of Life and Management of Living Resources, 
2009, 7: 212-224.

[28] Esterby-Smith M, Thorpe R, Lowe A. Management research: An introduction. Sege, London, 1991.

[29] Hair J F, Anderson R E, Tatham R L, et al. Multivariate data analysis with readings. Prentice-Hall, Upper Saddle River, New Jersey, 1998.

[30] Nunnally J C. Psychometric theory. 2nd ed. McGraw-Hill, New York, 1978.

[31] Nunnally J C, Bernstein I H. Psychometric theory. McGraw-Hill, New York, 1994.

[32] Fornell C, Larcker D F. Evaluating structural equation models with unobservable variables and measurement error. Journal Marketing Research, 1981, 18(1): 39-50.

[33] Segars A H. Assessing the unidimensionality of measurement: A paradigm and illustration within the context of information systems research. Omega, 1997, 25(1): 107-121.

[34] Baron R M, Kenny D A. The moderator-mediator variable distinction in social psychological research: Conceptual, strategic, and statistical considerations. Journal of Personality and Social Psychology, 1986, 51(6): 1173-1182.

[35] Yeung I Y M, Tung R L. Achieving business success in confucian societies: The importance of guanxi (connections). Organizational Dynamics, 1996(3): 54-65.

[36] Alston J P. Wa, guanxi and inhwa: Managerial principles in Japan, China, and Korea. Business Horizons, 1989, 3(4): 26-31.

[37] Tsang E W K. Can guanxi be a source of sustained competitive advantage in China? Academy of Management Executive, 1998(12): 64-73.

[38] Garrett S, Caldwell B. Describing functional requirements for knowledge sharing communities. Behaviour and Information Technology, 2002, 21(5): 359-364.

[39] Hall H. Input-friendliness: Motivating knowledge sharing across intranets. Journal of Information Science, 2001, 27(3): 139-146.

[40] Newell S, Bresnen M, Edelman L, et al. Sharing knowledge across projects: Limits to ICT-led project review practices. Management Learning, 2006, 37(2): 167-185.

[41] Choi S Y, Kang Y S, Lee H. The effects of socio-technical enablers on knowledge sharing: An exploratory examination. Journal of Information Science, 2008, 34(5): 742-754.

\section{Appendix: Questionnaire items}

\begin{tabular}{lcll}
\hline Construct & Items & Contents & Sources \\
\hline $\begin{array}{l}\text { Leader } \\
\text { Supporting }\end{array}$ & LS1 & $\begin{array}{l}\text { Project managers think that encouraging knowl- } \\
\text { edge sharing with colleagues is beneficial }\end{array}$ & \\
& LS2 & $\begin{array}{l}\text { Project managers always support and encour- } \\
\text { age employees to share their knowledge with col- } \\
\text { leagues }\end{array}$ & \\
& LS3 & $\begin{array}{l}\text { Project managers provide most of the necessary } \\
\text { help and resources to enable employees to share } \\
\text { knowledge }\end{array}$ & \\
& LS4 & $\begin{array}{l}\text { Project managers are keen to see that the employ- } \\
\text { ees are happy to share their knowledge with col- } \\
\text { leagues }\end{array}$ \\
\hline Interpersonal \\
relationship
\end{tabular}


continued

\begin{tabular}{|c|c|c|c|}
\hline \multirow[t]{3}{*}{$\begin{array}{l}\text { Knowledge } \\
\text { sharing } \\
\text { mechanism }\end{array}$} & SM1 & $\begin{array}{l}\text { The organization established a smooth informa- } \\
\text { tion exchange platform for knowledge sharing } \\
\text { The organization held meetings periodically or ir- } \\
\text { regularly for problem solving }\end{array}$ & \multirow[t]{3}{*}{$\begin{array}{l}\text { Wickramasinghe and } \\
\text { Widyaratne }^{[9]}\end{array}$} \\
\hline & SM3 & $\begin{array}{l}\text { The managers advocated collective wisdom to } \\
\text { solve problem }\end{array}$ & \\
\hline & SM4 & $\begin{array}{l}\text { The organization developed a detailed document } \\
\text { management system }\end{array}$ & \\
\hline \multirow[t]{4}{*}{$\begin{array}{l}\text { Organizational } \\
\text { incentive }\end{array}$} & OI1 & $\begin{array}{l}\text { Sharing my knowledge with colleagues should be } \\
\text { rewarded with a higher salary }\end{array}$ & \multirow[t]{4}{*}{$\operatorname{Lin}^{[19]}$} \\
\hline & OI2 & $\begin{array}{l}\text { Sharing my knowledge with colleagues should be } \\
\text { rewarded with a higher bonus }\end{array}$ & \\
\hline & OI3 & $\begin{array}{l}\text { Sharing my knowledge with colleagues should be } \\
\text { rewarded with a promotion }\end{array}$ & \\
\hline & OI4 & $\begin{array}{l}\text { Sharing my knowledge with colleagues should be } \\
\text { rewarded with an increased job security }\end{array}$ & \\
\hline \multirow{4}{*}{$\begin{array}{l}\text { Informal } \\
\text { knowledge } \\
\text { sharing }\end{array}$} & IS1 & $\begin{array}{l}\text { I usually share my experience with colleagues on } \\
\text { informal occasions }\end{array}$ & \multirow[t]{4}{*}{ Cao and Xiang ${ }^{[23]}$} \\
\hline & IS2 & $\begin{array}{l}\text { When I receive new information, I would share } \\
\text { with my collaborators in chat room or chatting } \\
\text { face-to-face }\end{array}$ & \\
\hline & IS3 & $\begin{array}{l}\text { I usually share my work documents and material } \\
\text { when collaborators in need }\end{array}$ & \\
\hline & IS4 & $\begin{array}{l}\text { I usually discuss problems encountered in the work } \\
\text { with my colleagues freely }\end{array}$ & \\
\hline \multirow{4}{*}{$\begin{array}{l}\text { Formal } \\
\text { knowledge } \\
\text { sharing }\end{array}$} & FS1 & $\begin{array}{l}\text { I usually share my report or useful files on formal } \\
\text { occasions }\end{array}$ & \multirow[t]{4}{*}{ Kremer $^{[17]}$} \\
\hline & FS2 & $\begin{array}{l}\text { I usually share my experience in a meeting or } \\
\text { through other official channels }\end{array}$ & \\
\hline & FS3 & $\begin{array}{l}\text { I usually write reports or articles about my pro- } \\
\text { fessional knowledge to share with my teammates }\end{array}$ & \\
\hline & FS4 & $\begin{array}{l}\text { When I receive new information, I would share } \\
\text { with my collaborators in a meeting or through } \\
\text { other official channels }\end{array}$ & \\
\hline
\end{tabular}

